\title{
Making Wise Choices When Incorporating Technology for Infection Control Prevention
}

\author{
Gustavo Wentz Biasuz • Ariádene Facco Espig • \\ Letícia D’Aló • Mariana Marques • \\ Flávia Julyana Pina Trench • Marcelo Carneiro
}

Published online: 20 November 2013

(C) Springer Science+Business Media New York 2013

\begin{abstract}
Healthcare workers are challenged with providing quality care in a variety of clinical settings, while optimizing the use of available resources. Although various novel approaches in preventing hospital-acquired infections (HAIs) have been introduced, best practices have yet to be consolidated. The use of sophisticated technology such as antiinfective devices can improve yields and reduce nosocomial infections while optimizing the use of staff time, but we would emphasize that this benefit is modest in most cases, and is easily undone when the focus of concern lies not in the
\end{abstract}

G. W. Biasuz • A. F. Espig • L. D’Aló • M. Marques • M. Carneiro Programa de Residência em Clínica Médica - Hospital Santa Cruz, Hospital Santa Cruz - Associação Pró-Ensino em

Santa Cruz do Sul - APESC, Santa Cruz do Sul, Brazil

G. W. Biasuz

e-mail: biasuz@gmail.com

A. F. Espig

e-mail: ariadeneespig@yahoo.com.br

L. D'Aló

e-mail: leticiadalo@gmail.com

M. Marques

e-mail: mary_marques22@hotmail.com

\section{F. J. Pina Trench}

Controle de Infecção do Hospital Ministro Costa Cavalcanti - Foz do Iguaçú - PR, Hospital Santa Cruz - Associação Pró-Ensino em Santa Cruz do Sul - APESC, Santa Cruz do Sul, Brazil

e-mail: flavia.trench@gmail.com

\section{Carneiro}

Controle de Infecção do Hospital Santa Cruz - Santa Cruz

do Sul - RS, Hospital Santa Cruz - Associação Pró-Ensino em Santa

Cruz do Sul - APESC, Santa Cruz do Sul, Brazil

M. Carneiro $(\bowtie)$

Rua Fernando Abott174, CEP: 96810-072 Santa Cruz do Sul, RS, Brazil

e-mail: carneiromarcelo@yahoo.com.br attention to proper aseptic technique, judicious use, and adequate clinical setting for these devices, but on poor implementation that relies only on their infection-prevention properties. This paper intends to review recent publications in key target areas regarding the prevention of HAIs and to discuss the incorporation of technology to achieve overall improvement in the healthcare setting.

Keywords ICU · Infection · Infection control ·

Healthcare-associated infection · Nosocomial infection .

Hand washing $\cdot$ Alcohol hand rub $\cdot$ Prevention $\cdot$ Bathing .

Environmental control $\cdot$ Implantable device $\cdot$ CLABSI .

Ventilator-associated pneumonia $\cdot$ VAP $\cdot$ Central line associated bloodstream infection $\cdot$ Surface decontamination . CAUTI $\cdot$ Air conditioning

\section{Purpose}

Healthcare workers are challenged with providing quality care in a variety of clinical settings, while optimizing the use of available resources. As physicians, we seek to offer our patients the best possible medical attention, and making use of available evidence is of paramount importance. Unfortunately, the high cost of some of the industry's technological interventions may restrict their applicability.

Certain advances in infection control practices and crosscontamination prevention have been difficult to implement, especially when low adherence, varying protocols, and equipment availability are taken into account. Although there have been novel approaches to preventing hospital-acquired infections (HAIs), best practices have yet to be consolidated. This paper will review recent publications in key target areas regarding the prevention of HAIs and will discuss the incorporation of technology to achieve overall improvement in the healthcare setting. 


\section{Methodology}

An internet search was performed in August of 2013 using the sites pubmed.com and pubget.com, with search parameter restricted to the last 36 months.

Several different permutations of these keywords were attempted in order to restrict the large volume of data acquired.

The scarcity of publications on some clinical issues precludes an ability to draw any useful conclusions. Therefore, in such instances, we cite experimental works that may lay the foundation for future investigation.

Inclusion criteria:

- Relevance to medical practice in hospital care settings

- Publication in the last three years

A few publications outside the 36-month time frame were added because they introduced important data or simply because there was no better information available.

Exclusion criteria:

Articles based exclusively on pediatric populations were disregarded if their conclusions could not be appropriately extrapolated to adult populations. As this could be interpreted as a high level of subjectivism, reader discretion is advised.

\section{General Prevention Measures}

\section{Antiseptic Bathing}

The colonized patient is a major reservoir for multidrugresistant organisms (MDROs) in the health care environment. Decreasing this reservoir may potentially decrease the risk of nosocomial transmission. One candidate strategy for decolonization of patients in the intensive care unit (ICU) environment is daily bathing with antiseptic washcloths $[1 \bullet, 2,3]$. Data suggest that any such strategies should be applied universally and not targeted at higher-risk patients [4•].

Although studies have used different protocols, there is evidence suggesting that daily chlorhexidine bathing is associated with a decreased rate of colonization by MDROs, as well as lower rates of catheter-related bloodstream infections (CLABSIs) $[1 \cdot, 2,3]$.

There are also reports regarding the impact of this measure in ventilator-associated pneumonia (VAP) prevention, although the association is not as clear, as incidence of VAP has shown no observable decrease. However, there appears to be a shift in the microbiological pattern from resistant to nonresistant organisms, possibly due to the already-reported lower MDRO colonization rates [5].

This approach is still under scrutiny in the preoperative environment, and a recent meta-analysis of available clinical trials suggested no appreciable benefit [6]. Methodological issues showed a remarkable diversity in the grouped studies [7] and therefore failed to sustain this lack of benefit when weighted with previous randomized control trial $[1 \bullet, 8]$.

\section{Oral Care}

As there is an association between changes in oropharyngeal bacteria and development of VAP, there are efforts underway aimed at oral decontamination and mechanical hygiene to control the bacteria responsible for infection. In light of this fact, tooth-brushing and the use of an oral antiseptic such as chlorhexidine are increasingly recommended in ventilator care bundles [9].

Unfortunately, the definition and implementation of oral hygiene protocols vary widely, and there is limited evidence to support their use. Moreover, the optimal frequency of oral decontamination and mechanical hygiene intervention has yet to be established [9]. A recent online survey showed that oral care was neither standardized nor consistently implemented in the intensive care units of the responding hospitals, and only a small proportion had protocols available for VAP prevention [10].

Evidence regarding critically ill patients undergoing mechanical ventilation indicates that the use of oral decontamination reduced the incidence of VAP but did not affect allcause mortality, duration of ventilation, or duration of ICU stay [11•]. With respect to mechanical hygiene, a recent systematic review and meta-analysis reported that tooth-brushing did not significantly reduce the overall risk of VAP [12•]. The same analysis suggests that the use of chlorhexidine decontamination seems to attenuate the effect of tooth-brushing on ventilator-associated pneumonia. As such, there is a lack of support for the use of mechanical hygiene when another effective oral decontamination strategy has already been implemented.

With regard to the preoperative environment, it is suggested that the use of a simple oral hygiene protocol can reduce postoperative pneumonia [13].

\section{Hand Hygiene}

Hand hygiene $(\mathrm{HH})$ decreases the transmission of microbial pathogens and is an effective and inexpensive infection control/prevention measure [14]. However, despite the fact that hand hygiene has been demonstrated as the singlemost important strategy in preventing and controlling healthcare-associated infections and the spread of multi-drug resistance organisms, studies have shown that hand hygiene compliance in healthcare settings remains suboptimal [15], even with adequate levels of selfreported awareness [16, 17].

Evidence does suggest that auditing local availability of hand hygiene materials and improving staff awareness could 
increase overall compliance $[18,19]$. It is not clear, however, if the use of more tolerant formulations (liquids, gels, or foams) would have a positive effect on compliance [20].

We suggest the use of an alcohol-based hand rub, as it requires less time than washing hands with chlorhexidine and water and is equally effective. We also suggest the use of pocket bottles, as this increases the availability of $\mathrm{HH}$ materials and has been associated with increased compliance. The greater issue is the lack of long-term continuity in the use of precautionary barriers when dealing with critically ill patients. Ongoing efforts are needed to reinforce the association between hand washing and a culture of quality care and commitment [21].

The monitoring of hand hygiene compliance is costly and labor-intensive. Additionally, there are drawbacks to the monitoring process simply by virtue of the fact that compliance numbers tend to be skewed, reflecting artificially high compliance during audits when staff are aware that they are being monitored [22]. Therefore, we believe that direct observation, measurement of volume use per patient-day, electronic devices, and automated reminders, while useful in promoting compliance [23, 24], are no substitute for complex interventions such as the WHO multimodal intervention strategy, which is feasible and sustainable across a wide range of settings and which has led to improvement in hand hygiene compliance [25, 26].

\section{Environmental Control}

\section{Room Isolation}

Contact isolation of patients has been recommended for the prevention and control of infection, but evidence supporting it in non-outbreak settings has been inconclusive [27]. Some clinical settings may respond more favorably to isolation procedures than others, in part due to varying mechanisms of transmission in the spread of infectious agents. There is significant evidence that room isolation appears to reduce cross-contamination of $C$. dificille, possibility due to the airborne spore dissemination mechanism [28].

There is also evidence that isolation rooms in the ICU may be an effective strategy to control and decrease the rate of hospital-acquired pneumonia [29], although it is not clear if the added benefit is due to increased compliance with other infection control measures such as hand washing and other contact barrier techniques [30-32]. It is also this author's opinion that understaffing might play a role, as this measure does increase cross-contamination opportunities, and research publications suggest a correlation between nurse understaffing and increased risk of nosocomial infection [33, 34].

\section{Surface Decontamination}

Contaminated surfaces in patient rooms have been linked to patient-to-patient transmission of several important nosocomial pathogens, including methicillin-resistant Staphylococcus aureus (MRSA), vancomycin-resistant Enterococcus, C. difficile, and multidrug-resistant gramnegative rods. Some of these pathogens are characterized by their ability to survive on inanimate surfaces for long periods of time, creating difficulties in controlling outbreaks [35].

Although environmental disinfectants have been used to minimize the spread of microbial pathogens, suboptimal cleaning may limit the effectiveness of such measures [35-37]. There is also the possibility that the MDRO persists on clinical surfaces despite adequate terminal cleaning, suggesting a lack of effectiveness in current anti-biofilm practices [38].

The use of audit and feedback with fluorescent targeting can be implemented across multiple clinical settings with only modest resources, resulting in rapid improvements in thoroughness of room cleaning [39]. Three promising new technologies that are effective, safe, and easy to use are hydrogen peroxide vapor, UV light decontamination, and ultramicrofibers with a copper-based biocidal agent [40].

Although conclusions regarding this issue in most trials cannot reasonably be isolated from other core practices in infection prevention and control, there is sufficient evidence to support the use of surface decontamination in the eradication of persistent environmental contamination with MRSA, multidrug-resistant gram-negative rods, and $C$. difficile infection [41, 42].

It is important to note that in outbreak settings, a systematic search for an environmental reservoir, followed by effective decontamination, may significantly reduce the incidence of nosocomial pathogen contamination $[42,43]$.

Another novel approach is the use of natural biocidal agents on the surface of objects such as copper alloys, which can contribute to the prevention of healthcare-associated infections. However, their use in clinical practice has not been sufficiently explored $[44,45]$.

\section{Air Conditioning and Lighting Fixtures}

At present, there is limited knowledge regarding the indoor transmission of pathogens, due in part to a lack of agreedupon definitions for particle types and mechanisms of transmission [46]. For this reason, it is possible that modern healthcare infrastructure design practices may favor pathogen persistence and transmission [47, 48], especially when considering spore-producing organisms [49].

Although novel air disinfection systems such as hydroxyl radical molecules are effective in reducing the number of airborne bacteria [50], evidence is still lacking with regard to 
their role in infection prevention. We believe future environmental recommendations will take into consideration mandatory air filtering or disinfection criteria, but at the moment, their effectiveness and impact are still a matter of speculation or low-level indirect evidence.

With regard to lighting fixtures in a controlled healthcare environment, there are virtually no publications concerning the use of sunlight and other specific technologies [46], and as current illumination guidelines are devised with no infection prevention in mind, it remains unknown whether environmental contamination can be addressed through the use of novel lighting technologies.

\section{Impregnated Devices}

Indwelling Urinary Catheter

Urinary tract infection (UTI) is common in the healthcare environment, and the incidence of UTI greatly increases with the use of an indwelling urinary catheter. Catheterassociated urinary tract infections (CAUTIs) are associated with MDROs and the development of bacteremia, and they are responsible for increased morbidity, hospital cost, and length of stay. Current strategies to prevent CAUTIs include limiting unnecessary catheterization, proper aseptic techniques, early catheter removal, and alternatives to indwelling catheters [51, 52]. Some research has also considered antimicrobial-impregnated urinary catheters, but these studies failed to address usable endpoints of morbidity and mortality reduction [53-56], possibly due to the use of obsolete definitions of CAUTI [57]. Despite this, we believe there is robust evidence that these catheters provide a small but tangible contribution in the prevention of infection.

Recent data suggest a small benefit in UTI prevention with the use of antibiotic prophylaxis at the time of catheter removal. However, there is insufficient evidence to recommend widespread usage. Moreover, there has been no determination of the patient population most likely to benefit from this approach [58].

It is our opinion that a "bladder bundle" approach is more useful in reducing unnecessary indwelling catheter use and in ensuring periodic assessment to determine whether continued use is appropriate. Since current data suggest that an infection-free scenario is not feasible, judicious use of this device appears to be the most rational approach [59, 60].

Endotracheal Tube

The use of invasive devices such as endotracheal tubes is associated with colonization of the respiratory tract and aspiration of contaminated secretions, and is part of the pathophysiology of ventilation-associated pneumonia. Several devices and strategies have been developed to counterbalance the effects of the breakdown of natural defense mechanisms, but no single strategy has been able to completely eliminate VAP.

The use of an endotracheal tube with silver coating has shown promising results in the prevention of VAP. This approach is an attractive alternative, as it has been demonstrated to significantly reduce the incidence of microbiologically confirmed VAP, with no notable adverse events. This is the first intervention that has become strategy-independent after intubation, requiring no further action from healthcare staff [61].

Another published approach is the use of specially modified subglottic secretion drainage (SSD), which involves a separate dorsal lumen that opens directly above the endotracheal tube cuff, enabling the aspiration of secretions and thereby reducing the risk of aspiration. A recent metaanalysis and multicenter controlled trial suggested that the use of SSD was beneficial in preventing VAP, and no notable adverse events were observed [62, 63]. Unfortunately, evidence is still lacking with regard to the best modality of intermittent or continuous aspiration of SSD in mechanically ventilated patients. We believe the current level of evidence is sufficient to incorporate these technologies into VAP bundles. The financial burden of either of these approaches is unknown but believed to be small.

\section{Central Venous Catheter}

Colonization of central venous catheter (CVC) surfaces by microbial pathogens appears to be a critical element in the pathogenesis of central line-associated bloodstream infection (CLABSI). Coating the catheters with antimicrobial substances limits microbial growth and is therefore thought to decreases the risk of subsequent infection. Studies regarding these antimicrobial-coated catheters (ACC) have demonstrated positive results, although methodological shortcomings preclude a recommendation for routine use. The effectiveness of this method remains to be determined, especially in settings where other infection prevention practices are already in place [64-67].

We concur with current CDC guidelines recommending the use of anti-infective devices in patients whose catheters are expected to remain in place for periods longer than 5 days if the implementation of other CLABSI prevention strategies is not producing expected results [68]. If the decision is made to use an antimicrobialimpregnated device, current data suggest superior performance in minocycline- and rifampicin-coated catheters, but there is no comprehensive assessment of this evidence in currently available publications [64]. 


\section{Conclusions}

The majority of issues regarding the prevention and control of infection appear to involve long-term systematic adherence to well-established best practices. The implementation of action bundles in critical care scenarios does engender a higher level of commitment on the part of healthcare institutions, which usually correlates to higher overall quality of care and lower rates of infection.

The use of sophisticated technology, such as anti-infective devices, has been demonstrated to improve yields and reduce nosocomial infection rates, while allowing for the optimal use of staff time. We would emphasize, however, that this benefit is modest in most cases, and it is easily undone when the focus of concern lies not on the attention to proper aseptic technique, judicious use, and adequate clinical setting of these devices, but on poor implementation that relies only on their infectionprevention properties.

\section{Compliance with Ethics Guidelines}

Conflict of Interest Gustavo Wentz Biasuz, Ariádene Facco Espig, Letícia D'Aló, Mariana Marques, Flávia Julyana Pina Trench, and Marcelo Carneiro declare that they have no conflicts of interest.

Human and Animal Rights and Informed Consent This article does not contain any studies with human or animal subjects performed by the authors.

\section{References}

Papers of particular interest, published recently, have been highlighted as

- Of importance

1. Climo MW, Yokoe DS, Warren DK, Perl TM, Bolon M, Herwaldt LA, et al. Effect of daily chlorhexidine bathing on hospital-acquired infection. N Engl J Med. 2013;368(24):2330-2. This study showed that chlorhexidine bathing is associated with a decreased rate of MDRO colonization, as well as lower rates of catheter-related bloodstream infections.

2. Singh Joy SD. Chlorhexidine-impregnated bathing cloths reduces risk of infection. Am J Nurs. 2013;113(8):62-3.

3. Montecalvo MA, McKenna D, Yarrish R, Mack L, Maguire G, Haas J, et al. Chlorhexidine bathing to reduce central venous catheter-associated bloodstream infection: impact and sustainability. Am J Med. 2012;125(5):505-11.

4. Huang SS, Septimus E, Kleinman K, Moody J, Hickok J, Avery $\mathrm{TR}$, et al. Targeted versus universal decolonization to prevent ICU infection. N Engl J Med. 2013;368(24):2255-65. This study suggests which chlorhexidine bathing modality could be employed.

5. Evans HL, Dellit TH, Chan J, Nathens AB, Maier RV, Cuschieri J. Effect of chlorhexidine whole-body bathing on hospital-acquired infections among trauma patients. Arch Surg. 2010;145(3):240-6.

6. Chlebicki MP, Safdar N, O'Horo JC, Maki DG. Preoperative chlorhexidine shower or bath for prevention of surgical site infection: a meta-analysis. Am J Infect Control. 2013;41(2):167-73.
7. Rauber JD, Carneiro M, Krummenauer EC, Machado JA, Valim AR. Preoperative chlorhexidine baths/showers: for or against? Am J Infect Control. 2013.

8. Kassakian SZ, Mermel LA, Jefferson JA, Parenteau SL, Machan JT. Impact of chlorhexidine bathing on hospital-acquired infections among general medical patients. Infect Control Hosp Epidemiol. 2011;32(3):238-43.

9. Andrews T, Steen C. A review of oral preventative strategies to reduce ventilator-associated pneumonia. Nurs Crit Care. 2013;18(3):116-22.

10. Gmür C, Irani S, Attin T, Menghini G, Schmidlin PR. Survey on oral hygiene measures for intubated patients in Swiss intensive care units. Schweiz Monatsschr Zahnmed. 2013;123(5):394-409.

11. Li J, Xie D, Li A, Yue J. Oral topical decontamination for preventing ventilator-associated pneumonia: a systematic review and meta-analysis of randomized controlled trials. J Hosp Infect. 2013;84(4):283-93. This study showed that the use of oral decontamination reduced the incidence of VAP.

12. Alhazzani W, Smith O, Muscedere J, Medd J, Cook D. Toothbrushing for critically ill mechanically ventilated patients: a systematic review and meta-analysis of randomized trials evaluating ventilator-associated pneumonia. Crit Care Med. 2013;41(2): 646-55. This study showed that tooth-brushing is not a requirement for oral decontamination.

13. Bergan EH, Tura BR, Lamas CC. Impact of improvement in preoperative oral health on nosocomial pneumonia in a group of cardiac surgery patients: a single arm prospective intervention study. Intensive Care Med. 2013. doi:10.1007/s00134-013-3049-y

14. Salama MF, Jamal WY, Mousa HA, Al-Abdulghani KA, Rotimi VO. The effect of hand hygiene compliance on hospital-acquired infections in an ICU setting in a Kuwaiti teaching hospital. J Infect Public Health. King Saud Bin Abdulaziz University for Health Sciences. 2013;6(1):27-34.

15. Lambert ML, Palomar M, Agodi A, Hiesmayr M, Lepape A, Ingenbleek A, et al. Prevention of ventilator-associated pneumonia in intensive care units: an international online survey. Antimicrob Resist Infect Control. 2013;2(1):9.

16. Carneiro M, Persch MS, Souza JG, Krummenauer EC, Machado JAA. What is the distance between saying and doing? Int J Infect Control. 2012;8(2). doi:10.3396/ijic.v8i2.020.12

17. Jessee MA, Mion LC. Is evidence guiding practice? Reported versus observed adherence to contact precautions: a pilot study. Am J Infect Control. 2013;41(11):965-70.

18. Azlz AM. How better availability of materials improved handhygiene compliance. Br J Nurs. 2013;22(8):458-63.

19. Chan BP, Homa K, Kirkland KB. Effect of varying the number and location of alcohol-based hand rub dispensers on usage in a general inpatient medical unit. Infect Control Hosp Epidemiol. 2013;34(9): 987-9.

20. Marra AR, Camargo TZ, Cardoso VJ, Moura DF Jr, Casemiro de Andrade E, Wentzcovitch J, et al. Hand hygiene compliance in the critical care setting: a comparative study of 2 different alcohol handrub formulations. Am J Infect Control. Elsevier Inc. 2013;41(2):136-9.

21. Rossi PJ, Edmiston Jr CE. Patient safety in the critical care environment. Surg Clin N Am. 2012;92(6):1369-86.

22. Daniels TL. Reconsidering hand hygiene monitoring. J Infect Dis. 2012;206(10):1488-90.

23. Sodré da Costa LS, Neves VM, Marra AR, Sampaio Camargo TZ, Fátima dos Santos Cardoso M, da Silva Victor E, et al. Measuring hand hygiene compliance in a hematology-oncology unit: a comparative study of methodologies. Am J Infect Control. 2013:41(11)997-1000.

24. Fisher DA, Seetoh T, Oh May-Lin H, Viswanathan S, Toh Y, Yin $\mathrm{WC}$, et al. Automated measures of hand hygiene compliance among healthcare workers using ultrasound: validation and a 
randomized controlled trial. Infect Control Hosp Epidemiol. 2013;34(9):919-28.

25. Reichardt CC, Königer D, Bunte-Schönberger K, van der Linden $P$, Mönch N, Schwab F, et al. Three years of national hand hygiene campaign in Germany: what are the key conclusions for clinical practice? J Hosp Infect. 2013;83 Suppl 1:S11-6.

26. Allegranzi B, Gayet-Ageron A, Damani N, Bengaly L, McLaws ML, Moro ML, et al. Global implementation of WHO's multimodal strategy for improvement of hand hygiene: a quasi-experimental study. Lancet Infect Dis. 2013;13:843-51.

27. Domenech de Cellès M, Zahar JR, Abadie V, Guillemot D. Limits of patient isolation measures to control extended-spectrum betalactamase-producing Enterobacteriaceae: model-based analysis of clinical data in a pediatric ward. BMC Infect Dis. 2013;13:187.

28. Best EL, Fawley WN, Parnell P, Wilcox MH. The potential for airborne dispersal of Clostridium difficile from symptomatic patients. Clin Infect Dis. 2010;50(11):1450-7.

29. Ucgun I, Dagli CE, Kiremitci A, Yildirim H, Ak G, Aslan S. Effects of isolation rooms on the prevalence of hospital acquired pneumonia in a respiratory ICU. Eur Rev Med Pharmacol Sci. 2013;17 Suppl 1:2-8.

30. Cheng VC, Tai JW, Chan WM, Lau EH, Chan JF, To KK, et al. Sequential introduction of single room isolation and hand hygiene campaign in the control of methicillin-resistant Staphylococcus aureus in intensive care unit. BMC Infect Dis. 2010;10(1):263.

31. Marshall C, Richards M, McBryde E. Do active surveillance and contact precautions reduce MRSA acquisition? A prospective interrupted time series. PLoS ONE. 2013;8(3):e58112.

32. Franca SR, Marra AR, de Oliveira Figueiredo RA, Pavão Dos Santos OF, Teodoro Ramos JC, Edmond MB. The effect of contact precautions on hand hygiene compliance. Am J Infect Control. 2013;41(6):558-9.

33. Rogowski JA, Staiger D, Patrick T, Horbar J, Kenny M, Lake ET. Nurse staffing and NICU infection rates. JAMA Pediatr. 2013;167(5):444-50.

34. Kiekkas P. Nurse understaffing and infection risk: current evidence, future research and health policy. Nurs Crit Care. 2013;18(2):61-2.

35. Huslage K, Rutala WA, Sickbert-Bennett E, Weber DJ. A quantitative approach to defining "high-touch" surfaces in hospitals. Infect Control Hosp Epidemiol. The University of Chicago Press; 2010;31(8):850-3.

36. Carling PC, Von Beheren SM, Kim P, Woods C, Group HEHS. Intensive care unit environmental cleaning: an evaluation in sixteen hospitals using a novel assessment tool. J Hosp Infect. 2008;68(1):6

37. Moore G, Muzslay M, Wilson AP. The type, level, and distribution of microorganisms within the ward environment: a zonal analysis of an intensive care unit and a gastrointestinal surgical ward. Infect Control Hosp Epidemiol. 2013;34(5):500-6.

38. Vickery K, Deva A, Jacombs A, Allan J, Valente P, Gosbell IB. Presence of biofilm containing viable multiresistant organisms despite terminal cleaning on clinical surfaces in an intensive care unit. J Hosp Infect. 2012;80(1):52-5.

39. Ragan K, Khan A, Zeynalova N, McKernan P, Baser K, Muller MP. Use of audit and feedback with fluorescent targeting to achieve rapid improvements in room cleaning in the intensive care unit and ward settings. Am J Infect Control. 2012;40(3):284-6.

40. Blazejewski C, Guerry MJ, Preau S, Durocher A, Nseir S. New methods to clean ICU. Infect Disord Drug Targets. 2011;11(4):36575 .

41. Falagas ME, Thomaidis PC, Kotsantis IK, Sgouros K, Samonis G, Karageorgopoulos DE. Airborne hydrogen peroxide for disinfection of the hospital environment and infection control: a systematic review. J Hosp Infect. 2011;78(3):171-7.

42. Chmielarczyk A, Higgins PG, Wojkowska-Mach J, Synowiec E, Zander E, Romaniszyn D, et al. Control of an outbreak of
Acinetobacter baumannii infections using vaporized hydrogen peroxide. J Hosp Infect. 2012;81(4):239-45.

43. La Forgia C, Franke J, Hacek DM, Thomson Jr RB, Robicsek A, Peterson LR. Management of a multidrug-resistant Acinetobacter baumannii outbreak in an intensive care unit using novel environmental disinfection: a 38-month report. Am J Infect Control. 2010;38(4):5.

44. Leite GC, Padoveze MC. Copper as an antimicrobial agent in healthcare: an integrative literature review. J Infect Control. 2012;1(2):33-6.

45. Salgado CD, Sepkowitz KA, John JF, Cantey JR, Attaway HH, Freeman KD, et al. Copper surfaces reduce the rate of healthcareacquired infections in the intensive care unit. Infect Control Hosp Epidemiol. 2013;34(5):479-86.

46. Hobday RA, Dancer SJ. Roles of sunlight and natural ventilation for controlling infection: historical and current perspectives. J Hosp Infect. 2013;84(4):271-82.

47. Boff C, Zoppas BC, Aquino VR, Kuplich NM, Miron D, Pasqualotto AC. The indoor air as a potential determinant of the frequency of invasive aspergillosis in the intensive care. Mycoses. 2013;56:527-31.

48. Grove DI, Lawson PJ, Burgess JS, Moran JL, O'Fathartaigh MS, Winslow WE. An outbreak of Legionella longbeachae infection in an intensive care unit? J Hosp Infect. 2002;52:250-8.

49. Roberts K. Aerial dissemination of Clostridium difficile spores. BMC Infect Dis. 2008;8(1):7.

50. Wong V, Staniforth K, Boswell TC. Environmental contamination and airborne microbial counts: a role for hydroxyl radical disinfection units? J Hosp Infect. 2011;78(3):194-9.

51. Hooton TM, Bradley SF, Cardenas DD, Colgan R, Geerlings SE, Rice JC, et al. Diagnosis, prevention, and treatment of catheterassociated urinary tract infection in adults: 2009 International Clinical Practice Guidelines from the Infectious Diseases Society of America. Clin Infect Dis. 2010;50:625-63.

52. Gould CV, Umscheid CA, Agarwal RK, Kuntz G, Pegues DA. Guideline for prevention of catheter-associated urinary tract infections 2009. Infect Control Hosp Epidemiol. 2010;31(4):319-26.

53. Beattie M, Taylor J. Silver alloy vs. uncoated urinary catheters: a systematic review of the literature. J Clin Nurs. 2011;20(15-16): 2098-108.

54. Davenport K, Keeley FX. Evidence for the use of silver-alloycoated urethral catheters. J Hosp Infect. 2005;60(4):298-303.

55. Davis K. Reduction in catheter-associated urinary tract infections (CAUTIs) using a silver-coated $100 \%$ silicone Foley catheter verses a silver-coated latex Foley catheter in a Northeastern U.S. acute care hospital. Am J Infect Control. 2005;33(5):e60.

56. Drekonja DM, Kuskowski MA, Wilt TJ, Johnson JR. Antimicrobial urinary catheters: a systematic review. Expert Rev Med Devices. 2008;5(4):495-506.

57. Press MJ, Metlay JP. Catheter-associated urinary tract infection: does changing the definition change quality? Infect Control Hosp Epidemiol. 2013;34(3):313-5.

58. Marschall J, Carpenter CR, Fowler S, Trautner BW, Trautner BW. Antibiotic prophylaxis for urinary tract infections after removal of urinary catheter: meta-analysis. CORD conference proceedings. BMJ. 2013;346:f3147.

59. Andreessen L, Wilde MH, Herendeen P. Preventing catheterassociated urinary tract infections in acute care. J Nurs Care Qual. 2012;27(3):209-17.

60. Saint S, Olmsted RN, Fakih MG, et al. Translating health careassociated urinary tract infection prevention research into practice via the bladder bundle. Jt Comm J Qual Patient Saf/Joint Commission Resources. NIH Public Access; 2009;35(9):449.

61. Kollef MH, Afessa B, Anzueto A, Veremakis C, Kerr KM, Margolis BD, et al. Silver-coated endotracheal tubes and incidence 
of ventilator-associated pneumonia: the NASCENT randomized trial. JAMA. 2008;300(7):805-13.

62. Wang F, Bo L, Tang L, Lou J, Wu Y, Chen F, et al. Subglottic secretion drainage for preventing ventilator-associated pneumonia: an updated meta-analysis of randomized controlled trials. J Trauma Acute Care Surg. 2012;72(5):1276-85.

63. Lacherade JC, De Jonghe B, Guezennec P, Debbat K, Hayon J, Monsel A, et al. Intermittent subglottic secretion drainage and ventilator-associated pneumonia: a multicenter trial. Am J Respir Crit Care Med. 2010;182(7):910-7.

64. Ramritu P, Halton K, Collignon P, Cook D, Fraenkel D, Battistutta $\mathrm{D}$, et al. A systematic review comparing the relative effectiveness of antimicrobial-coated catheters in intensive care units. Am J Infect Control. 2008;36(2):104-17.
65. Casey AL, Mermel LA, Nightingale P, Elliott TS. Antimicrobial central venous catheters in adults: a systematic review and metaanalysis. Lancet Infect Dis. 2008;8(12):14.

66. Hockenhull JC, Dwan KM, Smith GW, Gamble CL, Boland A, Walley TJ, et al. The clinical effectiveness of central venous catheters treated with anti-infective agents in preventing catheter-related bloodstream infections: a systematic review*. Crit Care Med. 2009;37(2):702-12.

67. Smulders CA, van Gestel JPJ, Bos AP. Are central line bundles and ventilator bundles effective in critically ill neonates and children? Intensive Care Med. 2013;39(8):1352-8.

68. O'Grady NP, Alexander M, Burns LA, Dellinger EP, Garland J, Heard SO, et al. Summary of recommendations: Guidelines for the prevention of intravascular catheter-related infections. Clin Infect Dis. 2011;52(9):1087-99. 